\title{
A STEP TOWARDS DEVELOPING A RUBBERIZED CONCRETE TO BE USED IN RC DEEP BEAMS
}

\author{
Ahmed Arafa ${ }^{a *}$, Nashwa Abdel Elghany ${ }^{\mathrm{b}}$, Omar A. Farghal ${ }^{\mathrm{b}}$, Abd-Elrahman \\ Megahed Ahmed \\ ${ }^{a}$ Civil Engineering Department, Faculty of Engineering, Sohag University, Sohag, 82524, Egypt \\ ${ }^{b}$ Civil Engineering Department, Faculty of Engineering, Assiut University, 71515, Egypt
}

\begin{abstract}
Using waste tire rubbers as a partial replacement of natural aggregates in conventional concrete materials can overcome many annoying environmental issues. In the literature, the experimental studies clearly revealed that the new concrete with rubber added have much lower compressive and tensile strength than the normal concrete as well as having a much better ductility and impact resistance. The studies mainly focused on small-scale specimens such as cubes, prisms and cylinders. There is a dearth in knowledge about the behavior of large-scale elements, especially such elements with brittle failure such as deep beams. The present study aimed at developing rubberized concrete with a minimal reduction in compressive, flexural and tensile strengths suitable for RC deep beams. Thirteen concrete mixtures were constructed: the first is a control normal concrete mixture and twelve other concrete mixtures with crumb rubber as a partial replacement of coarse aggregates. The parameters included the rubber replacement ratio $(5 \%, 10 \%, 20 \%$, and $30 \%)$, pre-treatment of rubber with NAOH and the use of silica fume powder as a partial replacement of cement. The results were analyzed considering the fresh and hardened concrete properties. It was shown that adding crumb rubber severely affected the concrete properties, but rubber pre-treatment while using silica fume noticeably controlled the reduction. Within the tested range of the rubber replacement ratio, it was found that the optimum ratio is $10 \%$ with an affordable $20 \%$ reduction in strength. This reduction is believed to be balanced by the safe disposal of waste tyres, the reduction in concrete density associated with the economic design and the concrete ductility.
\end{abstract}

(C) 2021 Published by Published by Faculty of Engineering - Sohag University. DOI: 10.21608/sej.2021.92961.1002

Keywords: Waste tyres, Rubberized concrete, Deep beams, Ductility.

\section{INTRODUCTION}

Waste tires represent a health hazard since tire piles are excellent breeding grounds for mosquitoes. In addition, waste rubber tires are known as the black pollution since they do not decompose and disintegrate in nature, posing a potential fire hazard to the environment at their storage locations. A large tire fire can continue for a long-time causing devastation as well as very harmful environment pollution. The disposal and treatment of nonbiodegradable waste tires is excessively expensive for any government $[1,2]$. Therefore, finding a technical economic solution to reuse and utilize these waste products in a sustainable environmentally friendly approach is a big challenge.

Extensive efforts were conducted around the globe to eliminate or even mitigate the waste tire stockpiles problems. To this end, concrete is the second most widely used material in the world that can consume large amounts of waste rubber tires by using them as a partial replacement for the routinely used aggregates [3-8]. One advantage of using crumb rubber as a partial replacement of aggregates is reducing the concrete density, since the density of rubber is much lower than the natural aggregate density. Furthermore, the non-polarity of rubber and the roughness of its surface result in introducing an additional quantity of air, namely because the nonpolar rubber rejects water and attracts air. The addition of rubber to the fresh concrete mixture was reported to inversely affect its workability, especially when a large amount is used. Given the inherent mechanical characteristics of rubber represented in the compressive strength and stiffness, excessive reduction in the concrete compressive strength has been reported. Recently, some studies have demonstrated that using such types of concrete can effectively improve the ductility and prevent brittle failures [9 - 14]. Such characteristics suggested that using waste tyre rubber-filled reinforced concrete would enhance the failure mechanism, toughness and ductility of the structural

\footnotetext{
* Corresponding author: ahmed_arafa@eng.sohag.edu.eg
} 
elements that suffer from brittle failure such as deep beams and columns. This benefit would be more effective if we could eliminate the reduction in compressive strength and the workability induced problem. Accordingly, this paper reports the preliminary testing conducted on rubberized concrete mixtures with coarse aggregate replacements. The aim is to focus on applying the previously tested treatment and report in the literature on locally produced materials. This is believed to be a step toward applying the most appropriate of crumb rubber replacement ratio to be used in different structural elements especially in deep beams in which control the brittle failure constitute a crucial issue in their design.

\section{EXPERIMENTAL PROGRAM}

Thirteen concrete mixtures were constructed and tested considering the fresh and hardened concrete properties. One concrete mixture was served as a reference, while the rest included crumb rubber as partial replacement of coarse aggregate. The studied parameters were the replacement ratio, crumb rubber treatment with $\mathrm{NAOH}$ and the use of silica fume as a partial replacement of cement. Four replacement ratios were tested (5\%, 10\%, 20\% and $30 \%$ by volume of gravel). For ease of referencing, the concrete mixtures are identified by the mixture type (R for refence specimen and $G$ for the mixtures in which the coarse aggregate was replaced by crumb rubber, respectively) followed with the replacement ratio. This was followed by two letters; $T$ for treated crumb rubber and $\mathrm{S}$ for the mixture in which a portion of cement was replaced with silica fume, if any. Table 1 lists the specimens' details.

TABLE 1. MiXTURE PROPORTIONS OF EACH BATCH OF CONCRETE, KG/M3

\begin{tabular}{|c|c|c|c|c|c|c|c|}
\hline \multirow{2}{*}{$\begin{array}{l}\text { Mix. } \\
\text { No. }\end{array}$} & \multirow[b]{2}{*}{ Mixture designation } & \multicolumn{5}{|c|}{ Mix proportions $\left(\mathrm{kg} / \mathrm{m}^{3}\right)$} & \multirow[b]{2}{*}{$\mathrm{Sp}$} \\
\hline & & Cement & $\begin{array}{l}\text { Silica } \\
\text { fume }\end{array}$ & $\begin{array}{c}\text { Coarse } \\
\text { aggregate }\end{array}$ & $\begin{array}{c}\text { Fine } \\
\text { aggregate }\end{array}$ & Rubber & \\
\hline 1 & MR-0CR & \multirow{9}{*}{400} & & 1127 & \multirow{13}{*}{624} & --------- & \multirow{13}{*}{9.5} \\
\hline 2 & MG-5CR & & & 1070 & & 18.7 & \\
\hline 3 & MG-10CR & & & 1014 & & 37.4 & \\
\hline 4 & MG-20CR & & & 901 & & 74.8 & \\
\hline 5 & MG-30CR & & ------ & 788 & & 112.2 & \\
\hline 6 & MG-5CR-T & & & 1070 & & 18.7 & \\
\hline 7 & MG-10CR-T & & & 1014 & & 37.4 & \\
\hline 8 & MG-20CR-T & & & 901 & & 74.8 & \\
\hline 9 & MG-30CR-T & & & 788 & & 112.2 & \\
\hline 10 & MG -5 CR- TS & \multirow{4}{*}{300} & \multirow{4}{*}{100} & 1070 & & 18.7 & \\
\hline 11 & MG -10 CR-TS & & & 1014 & & 37.4 & \\
\hline 12 & MG -20 CR-TS & & & 901 & & 74.8 & \\
\hline 13 & MG -30 CR- TS & & & 788 & & 112.2 & \\
\hline
\end{tabular}

Sp: Superplasticizer dosage,

\subsection{Materials}

Locally available materials were used in the tested concrete mixtures. Type I ordinary Portland cement was used. Silica fume from the Ferro silicon alloys produced by "SIKA Company" was used. River sand with a maximum aggregate size of $5 \mathrm{~mm}$ was used as a fine aggregate. The coarse aggregate used was natural gravel with a maximum aggregate size of $10 \mathrm{~mm}$ and specific gravity of 2.5 . A crumb rubber aggregate (with no steel wires) having a maximum size of $10 \mathrm{~mm}$, a specific gravity of 0.85 and a negligible absorption was used as a partial replacement of the coarse aggregate in the tested mixtures. To overcome the workability-induced problem, a superplasticizer called Sikament -NN (Produced by Sika company) was used.

\subsection{Pre-treatment of Rubber}

Many investigations in the literature documented that producing effective rubberized concrete required pretreatment of the rubber particles using a Sodium Hydroxide $(\mathrm{NaOH})$ solution to enhance the adhesion between the cement and the rubber [15-17]. The laboratory results revealed that the pre-treatment of rubber using a $\mathrm{NaOH}$ solution should be implemented within 30 minutes. Longer periods of treatment caused a negative effect on the concrete characteristics. Accordingly, in the present study, the used crumb rubber was immersed in a $10 \% \mathrm{NaOH}$ solution for 30 minutes only. Then, the rubber was washed with water to remove $\mathrm{NaOH}$. To show the effect of rubber pre-treatment, some control concrete mixtures were constructed without treatment.

\subsection{Mixing Procedure and Casting of Test Mixtures}

An electrical rotational drum mixer was used in concrete mixing. First, all coarse aggregates and fine aggregates (containing rubber aggregates) were poured into the mixer and mixed for 3 minutes, then mixed with all the 
added binders (cement and fly ash) for another 2 minutes. After dry mixing, half of the mixing water is added into the mixer for 2 minutes. Meanwhile, the super plasticizer was properly blended with the rest of the water. Finally, the remaining water and the admixtures were added to the mixer for 3 minutes of mixing, followed by 3 minutes of resting and another 2 minutes of terminal mixing.

\section{TEST METHODS AND RESULTS}

\subsection{Workability}

The workability of concrete is the ease with which concrete can be mixed, handled and compacted. As much as the concrete is properly compacted, the concrete could achieve maximum compressive strength. A concrete slump test or slump cone test was used in the present study to determine the workability or consistency of the test specimens (Fig. 1).

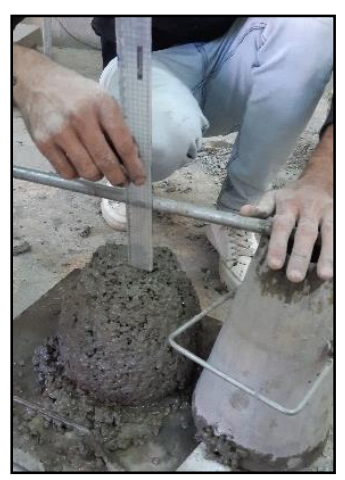

Fig. 1. Slump Test.

In the literature, it is well documented that adding crumb rubber adversely affects the concrete workability. This is one of many factors that cause a low compressive strength of rubberized concrete. This is due to the nonuniform shapes of the crumb rubber particles. To overcome this problem, adding a super plasticizer would be the most possible solution. Many trails have been conducted on the refence concrete to attain the maximum superplasticizer dosage as the concrete has no segregation or strength reduction. The results have showed that the most appropriate dosage is $2.25 \%$ according to the weight of the cement. Accordingly, this dosage was applied to all rubberized concrete mixture. Fig. 2 shows the results of the workability (slump test) for the control tested concrete mixtures. The results clearly indicated that adding crumb rubber caused a significant reduction in the concrete flowability. The higher the crumb rubber proportion the much lower the measured slump. For example, aggregate replacement with 5\%,10\%, 20\% and 30\% crumb rubber resulted in a slump reduction by $25 \%, 44 \%$, $60 \%$ and $75 \%$ respectively. The crumb rubber treatment has no effect on the concrete mixture's workability, while cement replacement with silica fume has a slight workability enhancement as shown in Fig. 2. Within the range of the tested rubber replacement ratio, using a 10\% replacement would be the most appropriate ratio for deep beams. Using higher ratios would be more appropriate in concrete in roads or other large sections.

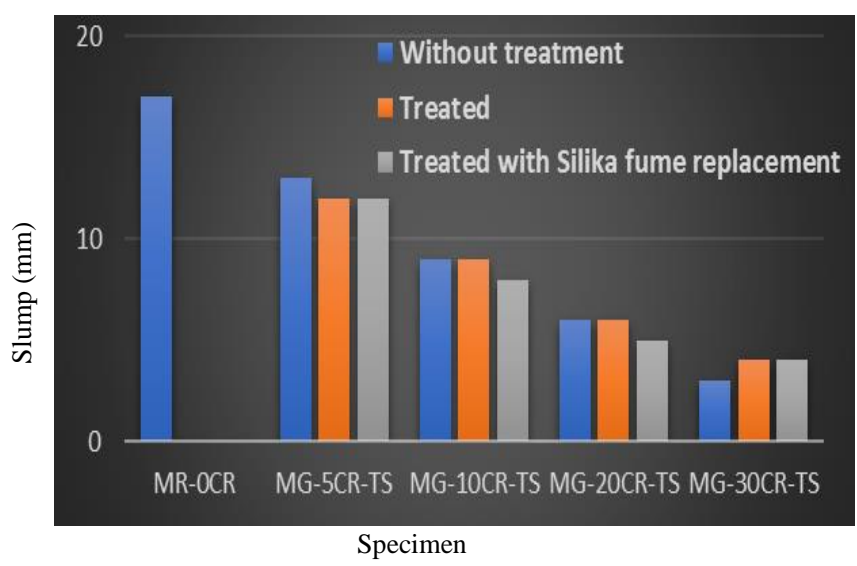

Fig. 2. Slump Results for all specimens. 


\subsection{Unit Weight}

The own weight of the structures represents more than $70 \%$ of the total load. The deep beam is a heavy structure element; therefore, using light concrete induced a significant reduction of reinforcement with a subsequent economic design. Crumb rubber has a much lower specific gravity than aggregate; in addition, the crumb rubber builds air content. Accordingly, increasing the rubber content significantly reduces the unit weight of the concrete. This is clear in Fig. 3. The use of rubber with a replacement ratio of 5\%, 10\%, $15 \%$ and $20 \%$ resulted in $7 \%, 11 \%$, $17 \%$ and $22 \%$ reduction in the unite weight respectively. Using the rubber pre-treatment or using silica fume had no effect, so it was removed from the figure. In conclusion, it can be inferred that the addition of rubber could be valuable for the formation of lightweight concrete in deep beams.

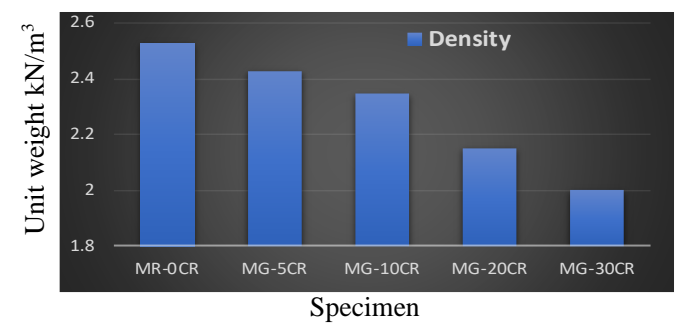

Fig. 3. Slump Results for all specimens.

\subsection{Compressive Strength Test}

Six cubes of dimensions $150 \times 150 \times 150 \mathrm{~mm}$ were prepared for each concrete mixture. The concrete was poured in the mold and appropriately tempered so as not to have any voids. After 24 hours, molds were removed and test specimens were put in water for curing. The specimens were tested by a compression testing machine after seven days curing or 28 days curing. A load was applied gradually at the rate of $140 \mathrm{~kg} / \mathrm{cm} 2$ per minute until the Specimens fail. The load at the failure divided by the area of the specimen gives the compressive strength of concrete (Fig. 4).
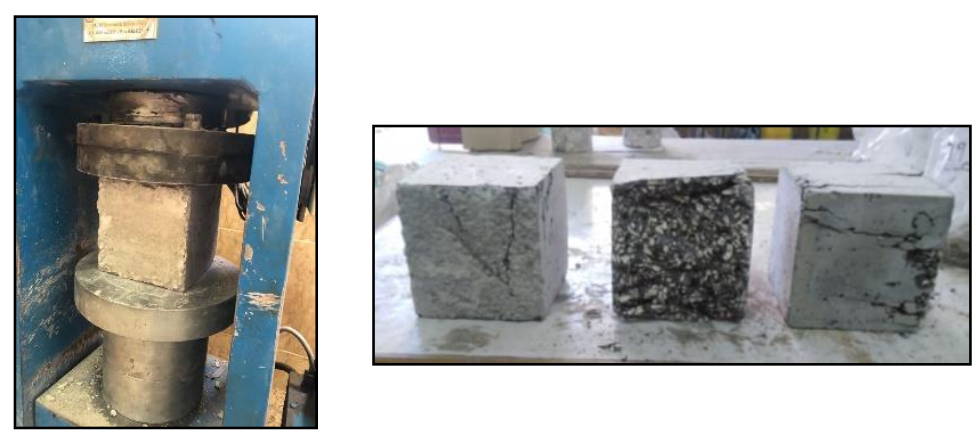

Fig. 4. Compressive Strength Test.

Fig. 5 compares the compressive strength for the test specimens. Apparently, a substantial reduction occurred in the compressive strength for the rubberized concrete without pre-treatment compared to the control concrete mixture. The reduction ratios in the compressive strength were respectively $13 \%, 35 \%, 58 \%$ and $65 \%$ corresponding to $5 \%, 10 \%, 20 \%$ and $30 \%$ of the rubber replacement ratio. Three main reasons can justify this reduction: 1) the low compressive strength of rubber compared to gravel; 2) the lower adhesive strength between the cement paste and the crumb rubber surface; 3) the voids in concrete induced by the non-uniform shape of crumb rubber. Accordingly, a lower compressive strength was recorded for the rubberized concrete compared to its reference. The rubber pre-treatment caused a slight enhancement, while the rubber pre-treatment with silica fume replacement showed the best results. The reduction ratios in the former were $10 \%, 29 \%, 52 \%$ and $57 \%$ respectively, while in the later were $6 \%, 21 \%, 41 \%$ and $51 \%$ respectively. Rubber treatment could enhance the adhesive strength between the cement paste and the rubber, while adding silica fume reduced the voids resulting in the enhancement of compressive strength. It is interesting to mention that normal concrete failure under compression is associated with shattering of the concrete when the failure was gradual with adding crumb rubber. As the amount of crumb rubber increased, the failure of concrete became more gradual. 


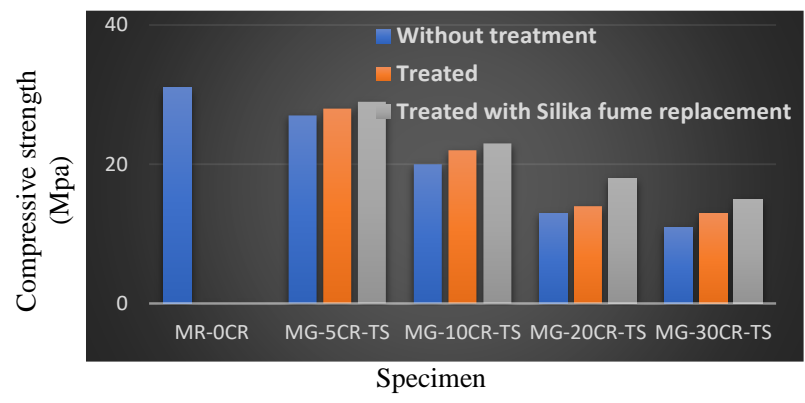

Fig. 5. Compressive Strength for the Test Specimens.

\subsection{Indirect Tensile Test}

The indirect (splitting) tensile test was applied on three $150 \times 300 \mathrm{~mm}$ cylindrical concrete specimens for each concrete mixture (Fig. 6). The splitting tensile strength was computed by using the average of the three samples using the following equation:

$$
f_{s p}=\frac{2 P}{\pi d L_{1}}
$$

where $f_{\mathrm{sp}}$ is the splitting tensile strength, $p$ is the maximum splitting tensile load, $L_{1}$ is the height of cylinder sample, $d=$ diameter of cylinder sample

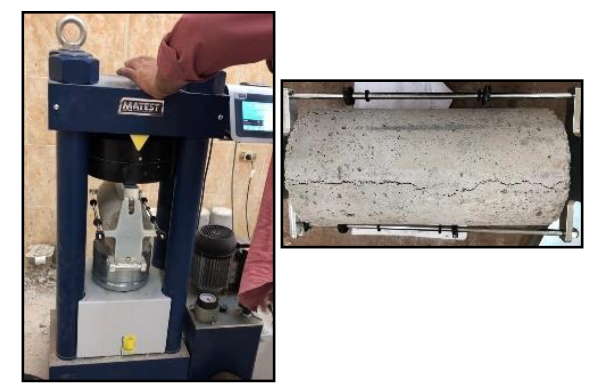

Fig. 6. Indirect Tensile Test

The tensile strength for the tested rubberized concrete specimens showed much lower tensile strength than the control specimen. The reduction in the tensile strength ranges were 9\%, 28\%, 53\% and $61 \%$ respectively for the tested range of rubber replacement ratio (Fig. 7). The reduction is attributed to the reduction in the compressive strength that is related to tensile strength, in addition to the existence of a void as well as the lower bond between the cement paste and the rubber. With rubber pre-treatment, there was no significant enhancement observed, while the use of silica fume in addition to the rubber pre-treatment gave the best results. In the latter case, the reduction in the tensile strength was $2 \%, 22 \%, 39 \%$ and $50 \%$ respectively.

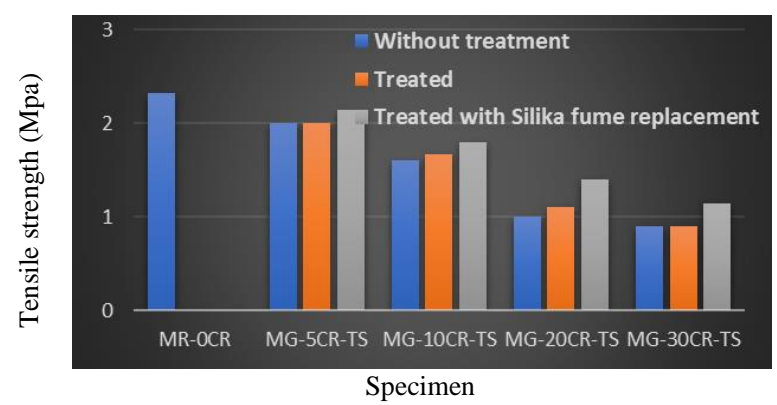

Fig. 7. Indirect Tensile Test. 


\subsection{Flexural Test}

Notched beams were constructed to determine the flexural strength of concrete mixtures. The specimens for flexural tests were cast in steel molds $(150 \times 150 \times 600 \mathrm{~mm})$ and the notch was realized on each sample before the execution of the test. According to the standard, the bending tests were carried out with a four-point loading beam scheme as shown in Fig. 8.

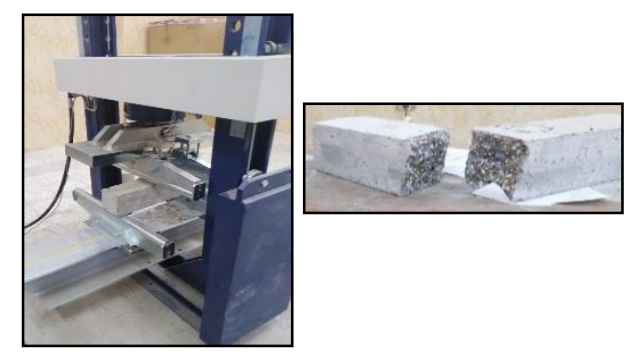

Fig. 8. Flexural Test.

Fig. 9 shows the calculated flexural strength for the test specimens. Similar to the tensile strength, there is noticeable reduction in the rubberized concrete flexural strength. However, the range of reduction is slightly lower, since the reduction ratio ranged between $8-49 \%$ for rubberized concrete without rubber pre-treatment. Similarly, the use of silica fume replacement with the rubber pre-treatment showed the best results. The reduction in strength was $4 \%, 16 \%, 29 \%$ and $36 \%$ corresponding to $5 \%, 10 \%, 20 \%$ and $30 \%$ respectively.

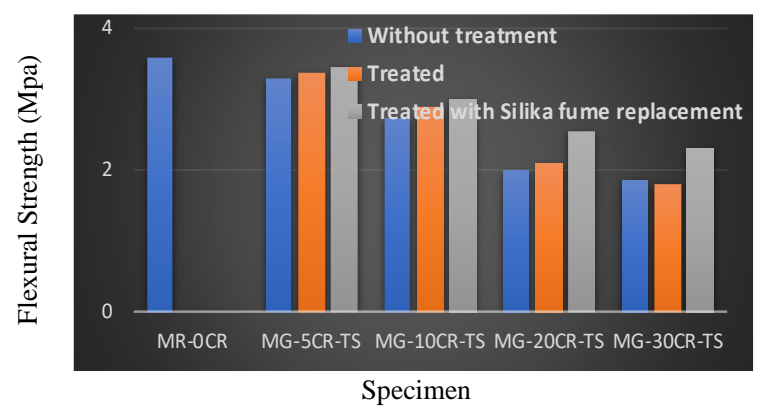

Fig. 9. Flexural Strength for the test specimens.

\section{DISCUSSION AND CONCLUSIONS}

Serving the target of this paper, it is of interest to show the optimum ratio for the crump rubber replacement to be used in deep beams. From the results, it is observed that using silica fume in addition to the rubber pre-treatment is necessary to mitigate the strength reduction of rubberized concrete. By doing so and within the tested range of rubber replacement ratio, adding crumb rubber higher than $10 \%$ of the weight of the coarse aggregate is associated with an unbearable strength reduction. This level was associated with $21 \%, 22 \%$ and $16 \%$ reduction in the compressive, tensile and flexural strength respectively. This would be affordable and can be equalized by the benefits from the rubber replacement represented in the safe disposal of waste tires, reduction in the structure weight and the gradual failure of deep beams with a wide range of warning. More laboratory tests are being implemented to study the effect of using rubber as a partial replacement for the fine aggregate and to reach the most appropriate concrete mixture to be tested in large-scale deep beams.

\section{References}

[1] X. Shu, and B. Huang, "Recycling of Waste Tire Rubber in Asphalt and Portland Cement Concrete: An Overview," Construction and Building Materials, Vol 67, pp. 217-224, 2014.

[2] S. Guo; J. Hu; and Q. Dai, "A Critical review on the performance of Portland cement concrete with recycled organic components," Journal of Cleaner Production, Vol 188, pp. 92-112, 2018.

[3] Rindl, J., Recycling Manager, report by Recycling manager. Dane Country, Department of Public Works, Madison, USA, 1998.

[4] C. Pierce, and M. Blackwell, "Potential of scrap tire rubber as lightweight aggregate in flowable fill," Waste Management, Vol 23, No 3, pp. 197-208, 2003.

[5] R. Siddique, and T.R. Naik, "Properties of concrete containing scrap-tire rubber-an overview," Waste management, Vol 24, No 6: pp. 563-569, 2004. 
[6] M.K. Batayneh, I. Marie, and I. Asi, "Promoting the use of crumb rubber concrete in developing countries," Waste Management, Vol 28, No 11, pp. 2171-2176. 2008.

[7] N. Segre, and I. Joekes, "Use of tire rubber particles as addition to cement paste." Cement and Concrete Research, Vol 30, No 9, pp. 1421-1425, 2000.

[8] Q. Dong, B. Huang, and X. Shu, "Rubber modified concrete improved by chemically active coating and silane coupling agent," Construction and Building Materials, Vol 48: pp. 116-123, 2013.

[9] R. Siddique, and T.R. Naik, "Properties of concrete containing scrap-tire rubber--an overview," Waste Manag, Vol 24, No 6, pp. 563-9, 2004.

[10] B. Huang, X. Shu, and J. Cao, "A two-staged surface treatment to improve properties of rubber modified cement composites," Construction and Building Materials, Vol 40, p. 270-274, 2013.

[11] G. Li "Development of waste tire modified concrete," Cement and Concrete Research, Vol 34, No 12, pp. 2283-2289, 2004.

[12] F. Herna 'ndez-Olivares, G.B., M. Bollati, B. Witoszek, "Static and dynamic behaviour of recycled tyre rubber-filled concrete," Cement and Concrete Research, Vol 32, pp. 1587-1596, 2002.

[13] F. Hernández-Olivares, and G. Barluenga, "Fire performance of recycled rubber-filled high-strength concrete." Cement and Concrete Research, Vol 34, No 1, pp. 109-117. 2004

[14] N. Segre, I. Joekes, "Use of tire rubber particles as addition to cement paste," Cem. Concr. Res. Vol 30, No 9, pp. 14211425,2000

[15] R. Siddique, T.R. Naik, "Properties of concrete containing scrap-tire rubber-an overview," Waste Manage. Vol 24, No 6, pp. 563-569, 2004.

[16] O. Youssf, J.E. Mills, R. Hassanli, "Assessment of the mechanical performance of crumb rubber concrete," Constr. Build. Mater., Vol 125, pp.175-183. 2016. 